\title{
Stoichiometric imbalance-promoted synthesis of polymers containing highly substituted naphthalenes: rhodium-catalyzed oxidative polycoupling of arylboronic acids and internal diynes
}

\author{
Meng Gao, ${ }^{a}$ Jacky W. Y. Lam, ${ }^{\text {Jie Li, }}{ }^{a}$ Carrie Y. K. Chan, ${ }^{a}$ Yilong Chen, ${ }^{a}$ Na Zhao, ${ }^{a}$ \\ Tianyu Han ${ }^{a}$ and Ben Zhong Tang*ab \\ A new route for the synthesis of functional polymers was developed. Oxidative polycoupling of $4,4^{\prime}-(\alpha, \omega-$ \\ alkylenedioxy) bis(diphenylacetylene)s with phenylboronic acid and (1,1,2-triphenylvinyl)phenylboronic \\ acid, respectively, was catalyzed by $\left[\mathrm{Cp}^{*} \mathrm{RhCl}_{2}\right]_{2}$ and oxidants in dimethylformamide, affording soluble \\ polymers with highly substituted naphthalene rings in satisfactory yields with moderate molecular \\ weights. All the polymers were thermally and morphologically stable, showing high thermal- \\ degradation and glass-transition temperatures of $317-404{ }^{\circ} \mathrm{C}$ and $95-168{ }^{\circ} \mathrm{C}$, respectively. They were \\ film-forming and their thin solid films showed high refractive indices $(\mathrm{RI}=1.7414-1.6038)$ in a wide \\ wavelength region of 400-1600 $\mathrm{nm}$. The polymer carrying tetraphenylethene unit was weakly emissive \\ in solution but emitted intensely in the condensed phase, displaying a phenomenon of aggregation- \\ induced emission. The emission of its nanoaggregates could be quenched by picric acid with large \\ quenching constants, making it promising as a sensitive chemosensor for efficient detection of explosives.
}

Received 17th September 2012 Accepted 17th October 2012

DOI: $10.1039 /$ c2py20758c

www.rsc.org/polymers propargyl carbonates and bisphenols ${ }^{5}$ and synthesis of polyorthocarbonates, ${ }^{6}$ polythioethers ${ }^{7}$ and poly(phenylene ethynylene)s. ${ }^{8}$ A common feature of these polymerizations is that the first reaction of the bifunctional monomer significantly facilitates the second reaction of the remaining functional group.

$$
\begin{gathered}
X_{\mathrm{n}}=(1+r) /(1+r-2 r p) \\
X_{\mathrm{n}}=(1+r) /(1-r)
\end{gathered}
$$

Highly substituted naphthalene derivatives have attracted much attention because of their good stability and solubility as well as photo- and electrochemical properties. ${ }^{9}$ To reduce wastes generated during their preparation, great attention has been paid to synthetic methods based on carbon-hydrogen (C-H) bond activation, ${ }^{10}$ which allows direct transformation of substrates with inert $\mathrm{C}-\mathrm{H}$ bonds to functionalized naphthalene derivatives. ${ }^{11}$ Among them, the rhodium-catalyzed oxidative coupling reaction of arylboronic acids and internal alkynes reported by Satoh and Miura et al. is an interesting approach as the presence of excess boronic acids would not influence the reaction efficiency. ${ }^{11 a, b}$ While such a method is versatile for the synthesis of low molecular weight naphthalene derivatives, little effort has been made to develop it into a useful stoichiometric imbalance-promoted polymerization tool for the preparation of acetylenic polymers. ${ }^{12}$ In this paper, we explored such possibility and showed that the poly(naphthalene)s obtained under 


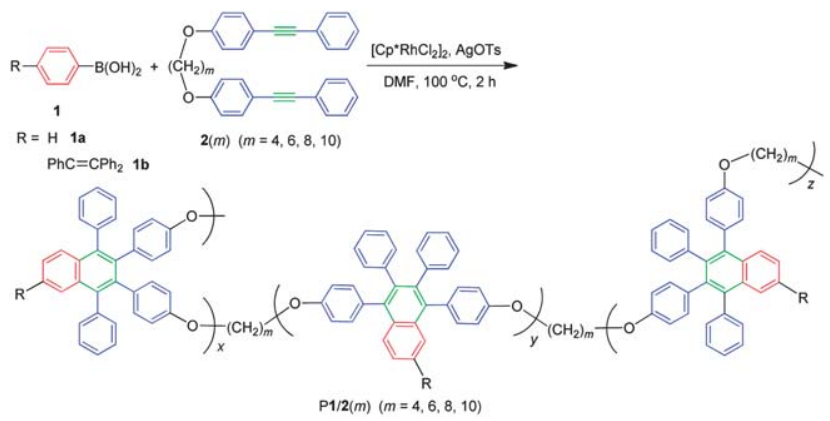

Scheme 1 Rhodium-catalyzed oxidative polycoupling of boronic acid 1 and internal diynes $\mathbf{2}(m)$.

optimized conditions exhibit good solubility and thermal stability, high light refractivity and interesting aggregationinduced emission (AIE) property (Scheme 1).

\section{Results and discussion}

\section{Monomer synthesis}

To widen the methodology for the synthesis of functional polymers from acetylene building blocks, we prepared arylboronic acids 1 with different aromatic rings. While 1a was commercially available, $\mathbf{1 b}$ was prepared according to our previous publication (Scheme 1). ${ }^{13}$ We also designed the molecular structures of four internal diynes with different spacer lengths $[2(m)(m=2,4,6$, and 8$)]$ and elaborated a twostep reaction route for their synthesis. We first prepared 4 -(phenylethynyl)phenol by Sonogashira coupling reaction ${ }^{14}$ of 4-iodophenol and phenylacetylene, whose reaction with $\alpha, \omega$-dibromoalkanes afforded the desired products $2(\mathrm{~m})$ (Scheme 2). ${ }^{15}$ All the monomers were characterized by standard spectroscopic methods and gave satisfactory analysis data corresponding to their structures (see data given in the Experimental section).

\section{Model reaction}

We first carried out a model reaction of phenylboronic acid with unsymmetric internal alkyne $\mathbf{4}$ to assist structural characterization (Scheme 3). The reaction was carried out at a two-fold excess amount of 1a catalyzed by $\left[\mathrm{Cp}^{*} \mathrm{RhCl}_{2}\right]_{2}$ and AgOTs in DMF at $100{ }^{\circ} \mathrm{C}$ under a nitrogen atmosphere, which theoretically generated three naphthalene derivatives 5-7 in a total yield of $82 \%$ after purification. Since 5-7 possess similar physical properties, it is hard to separate them by column

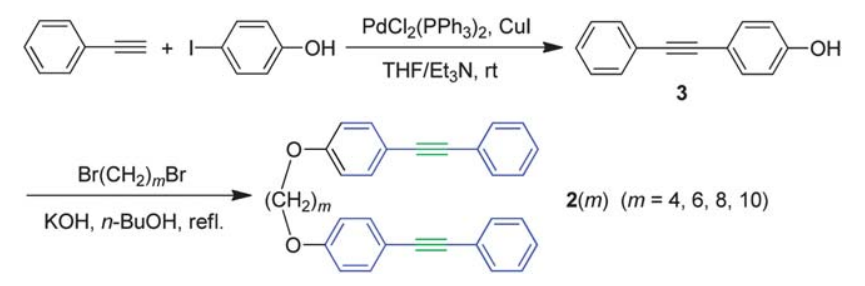

Scheme 2 Synthesis of internal diyne monomers $\mathbf{2}(m)$.
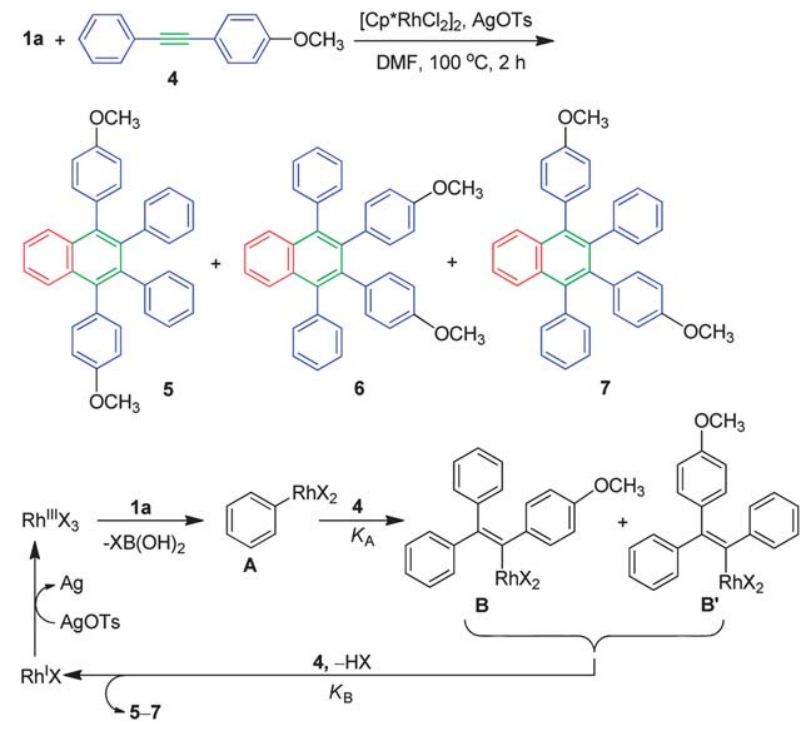

Scheme 3 Rhodium-catalyzed oxidative coupling of $\mathbf{1 a}$ and internal alkyne $\mathbf{4}$ and its associated mechanism.

chromatography. They almost resonate at similar chemical shifts, making it difficult to determine their ratios by ${ }^{1} \mathrm{H}$ NMR spectroscopy. Their high resolution mass spectrum exhibits $\mathrm{M}^{+}$ peak at 492.2090 , in good agreement with the calculated value (492.2089).

The mechanism for such a reaction involved first transmetallation of $\mathrm{Rh}^{\mathrm{III}} \mathrm{X}_{3}$ species with 1a to generate an arylrhodium intermediate A. Insertion of $\mathbf{4}$ into $\mathbf{A}$ formed two vinylrhodium species $\mathbf{B}$ and $\mathbf{B}^{\prime}$. Subsequent insertion of the second alkyne molecule into $\mathbf{B}$ and $\mathbf{B}^{\prime}$ followed by reductive elimination afforded a mixture of 5-7. The resulting $\mathrm{Rh}^{\mathrm{I}} \mathrm{X}$ species were oxidized by silver salts such as AgOTs to regenerate $\mathrm{Rh}^{\mathrm{III}} \mathrm{X}_{3}$. Since the insertion of the first alkyne molecule significantly facilitates the annulation reaction of the second one, the addition of excess amount of $1 \mathbf{a}$ into the reaction mixture will accelerate the formation of intermediates $\mathbf{B}$ and $\mathbf{B}^{\prime}$, making the polymerization more efficient. ${ }^{11 a, b}$ However, due to the difference in the rate of alkyne insertion $\left(K_{\mathrm{A}} \ll K_{\mathrm{B}}\right)$, alkyne groups will always exist at the polymer ends. This prevents termination of the polymer chains by intrachain cyclization and promotes the formation of high molecular weight polymers. ${ }^{16}$

\section{Polymerization}

To search for optimum parameters, we first studied the effect of different oxidants on the polymerization using $\mathbf{1 a}$ and 2(4) as monomers. In the presence of a catalytic dose of $\mathrm{Cu}(\mathrm{OAc})_{2} \cdot \mathrm{H}_{2} \mathrm{O}$, a polymer was obtained in a moderate yield of $77 \%$ with an $M_{\mathrm{w}}$ value of 7000 under air for $2 \mathrm{~h}$ (Table 1, no. 1). When a quantitative amount of $\mathrm{Cu}(\mathrm{OAc})_{2} \cdot \mathrm{H}_{2} \mathrm{O}$ was used, the yield and molecular weight of the polymer, however, decreased significantly. We then screened the catalytic activity of different silver oxidants (AgOTs, $\mathrm{AgCF}_{3} \mathrm{SO}_{3}, \mathrm{AgCF}_{3} \mathrm{CO}_{2}, \mathrm{AgSbF}_{6}$ and $\mathrm{AgNO}_{3}$ ). Among them, AgOTs revealed the best result, giving a polymer with the highest molecular weight of 9200 in over $80 \%$ yield 
Table 1 Effects of oxidants and temperature on the polymerization of $1 \mathbf{a}$ and $\mathbf{2}(4)^{a}$

\begin{tabular}{lllllll}
\hline No. & Oxidant & $\begin{array}{l}{[\text { Oxidant }]} \\
(\mathrm{M})\end{array}$ & $\begin{array}{l}\text { Temp. } \\
\left({ }^{\circ} \mathrm{C}\right)\end{array}$ & $\begin{array}{l}\text { Yield } \\
(\%)\end{array}$ & $M_{\mathrm{w}}{ }^{c}$ & $M_{\mathrm{w}} / M_{\mathrm{n}}{ }^{c}$ \\
\hline $1^{b}$ & $\mathrm{Cu}(\mathrm{OAc})_{2} \cdot \mathrm{H}_{2} \mathrm{O}$ & 0.025 & 100 & 77 & 7000 & 1.8 \\
2 & $\mathrm{Cu}(\mathrm{OAc})_{2} \cdot \mathrm{H}_{2} \mathrm{O}$ & 0.20 & 100 & 67 & 5500 & 2.1 \\
3 & $\mathrm{AgOTs}_{4}$ & 0.20 & 100 & 83 & 9200 & 1.9 \\
5 & $\mathrm{AgCF}_{3} \mathrm{SO}_{3}$ & 0.20 & 100 & 71 & 4100 & 1.5 \\
6 & $\mathrm{AgCF}_{3} \mathrm{CO}_{2}$ & 0.20 & 100 & 67 & 4200 & 1.6 \\
7 & $\mathrm{AgSbF}_{6}$ & 0.20 & 100 & 35 & 3900 & 1.6 \\
8 & $\mathrm{AgNO}_{3}$ & 0.20 & 100 & 29 & 2200 & 1.5 \\
9 & AgOTs & 0.20 & 80 & 80 & 8800 & 2.0 \\
& AgOTs & 0.20 & 60 & 43 & 5700 & 1.9
\end{tabular}

${ }^{a}$ Carried out in DMF at $100{ }^{\circ} \mathrm{C}$ under a nitrogen atmosphere for $2 \mathrm{~h}$ in the presence of $\left[\mathrm{Cp}^{*} \mathrm{RhCl}_{2}\right]_{2}$ and different oxidants. $[\mathbf{1 a}]=0.20 \mathrm{M}$, $[2(4)]=0.10 \mathrm{M}$, and $[\mathrm{Rh}]=5 \mathrm{mM} .{ }^{b}$ Under air. ${ }^{c}$ Estimated by GPC in THF on the basis of a polystyrene calibration.

after reaction in DMF at $100{ }^{\circ} \mathrm{C}$ for $2 \mathrm{~h}$. Lowering the temperature to $80{ }^{\circ} \mathrm{C}$ affected the polymerization result little but a polymer with a much lower molecular weight was isolated in a lower yield at $60{ }^{\circ} \mathrm{C}$.

We then investigated the influence of monomer concentration on the polymerization. When the concentrations of $\mathbf{1 a}$ and 2(4) were increased progressively from $0.05 \mathrm{M}$ and $0.025 \mathrm{M}$ to $0.20 \mathrm{M}$ and $0.10 \mathrm{M}$, respectively, keeping the molar ratio unchanged, both the isolated yield and molecular weight of the polymer were enhanced accordingly (Table 2, nos 1-4). The polymerization of 1a and 2(4) carried out at a molar ratio of $1: 1$ gave a slightly poorer result (Table 2, no. 5). Thus, it seems that it is beneficial to perform the polymerization in an excess amount of $\mathbf{1 a}$.

Table 2 Effect of concentration on the polymerization of $\mathbf{1 a}$ and $\mathbf{2}(4)^{\mathrm{a}}$

\begin{tabular}{|c|c|c|c|c|c|c|c|}
\hline No. & $\begin{array}{l}{[1 \mathrm{a}]} \\
\text { (M) }\end{array}$ & $\begin{array}{l}{[2(4)]} \\
(\mathrm{M})\end{array}$ & $\begin{array}{l}{[\mathrm{Rh}]} \\
(\mathrm{mM})\end{array}$ & $\begin{array}{l}\text { AgOTs } \\
\text { (M) }\end{array}$ & $\begin{array}{l}\text { Yield } \\
(\%)\end{array}$ & $M_{\mathrm{w}}{ }^{b}$ & $M_{\mathrm{w}} / M_{\mathrm{n}}^{b}$ \\
\hline 1 & 0.05 & 0.025 & 1.25 & 0.05 & 48 & 4700 & 1.9 \\
\hline 2 & 0.10 & 0.05 & 2.5 & 0.10 & 72 & 6400 & 2.0 \\
\hline 3 & 0.15 & 0.075 & 3.75 & 0.15 & 79 & 8100 & 1.8 \\
\hline 4 & 0.20 & 0.10 & 5.0 & 0.20 & 83 & 9200 & 1.9 \\
\hline 5 & 0.10 & 0.10 & 5.0 & 0.20 & 74 & 8400 & 2.2 \\
\hline
\end{tabular}

${ }^{a}$ Carried out in DMF at $100{ }^{\circ} \mathrm{C}$ under a nitrogen atmosphere for $2 \mathrm{~h}$. ${ }^{b}$ Estimated by GPC in THF on the basis of a polystyrene calibration.

Table $\mathbf{3}$ Polymerization of $\mathbf{1}$ and $\mathbf{2}(\mathrm{m})$ under optimized conditions ${ }^{\mathrm{a}}$

\begin{tabular}{lllll}
\hline No. & Polymer & Yield (\%) & \multicolumn{1}{c}{$M_{\mathrm{w}}{ }^{b}$} & $M_{\mathrm{w}} / M_{\mathrm{n}}{ }^{b}$ \\
\hline 1 & $\mathrm{P} 1 \mathrm{a} / \mathbf{2}(4)$ & 83 & 9200 & 1.9 \\
2 & $\mathrm{P} 1 \mathrm{a} / \mathbf{2}(6)$ & 80 & 10500 & 2.0 \\
3 & $\mathrm{P} 1 \mathbf{2}(8)$ & 78 & 9100 & 2.0 \\
4 & $\mathrm{P} 1 \mathrm{a} / 2(10)$ & 62 & 6300 & 1.8 \\
5 & $\mathrm{P} 1 \mathrm{~b} / 2(6)$ & 86 & 11600 & 2.1
\end{tabular}

${ }^{a}$ Reaction at $100{ }^{\circ} \mathrm{C}$ under a nitrogen atmosphere for $2 \mathrm{~h}$ in the presence of $\left[\mathrm{Cp}^{*} \mathrm{RhCl}_{2}\right]_{2}$ and AgOTs. $[1]=0.20 \mathrm{M},[2(\mathrm{~m})]=0.10 \mathrm{M}$, $[\mathrm{Rh}]=5 \mathrm{mM}$, and $[\mathrm{AgOTs}]=0.20 \mathrm{M} .{ }^{b}$ Estimated by GPC in THF on the basis of a polystyrene calibration.
The above systematic studies enable us to polymerize other monomers under optimal conditions (Table 3). All the polymerization reactions proceeded smoothly, giving their corresponding polymers in good yields with high molecular weights (Table 3, nos 1-5). Because of the irregular distribution of the repeating units of 5-7, the polymers showed good solubility in common organic solvents, such as dichloromethane (DCM), chloroform, tetrahydrofuran (THF) and toluene, and could fabricate into good solid films by spin-coating or static-casting processes.

\section{Structural characterization}

The structures of the polymers were characterized by standard spectroscopic methods with satisfactory results. The IR spectrum of P1a/2(4) is given in Fig. 1 as an example; for comparison, the spectra of $\mathbf{1 a}$ and 2(4) are also given in the same figure. The spectrum of $\mathbf{P 1 a} / 2(4)$ showed absorption peaks inherited from 1a and 2(4) except for those associated with $\mathrm{B}-\mathrm{O}$ and $\mathrm{C} \equiv \mathrm{C}$ stretching vibrations at $1343 \mathrm{~cm}^{-1}$ and $2218 \mathrm{~cm}^{-1}$, respectively.

Fig. 2 shows the ${ }^{1} \mathrm{H}$ NMR spectra of P1a/2(4), 1a, 2(4) and a mixture of 5-7. The absorption peak at $\delta 8.26$ in 1a was assigned to the resonance of the phenyl protons adjacent to the boronic acid group, which disappeared completely in the spectrum of $\mathrm{P1a} / 2(4)$. Instead, new peaks emerged at the aromatic absorption regions of $\delta 7.67-7.61$ and 6.72-6.35 due to the formation of new naphthalene ring in the polymer. The absorption peaks observed for P1a/2(4) were much broader than those of 5-7, revealing its polymeric nature.

The ${ }^{13} \mathrm{C}$ NMR spectroscopy offers more informative analysis data (Fig. 3). For example, the ${ }^{13} \mathrm{C}$ NMR spectrum of P1a/2(4) exhibited no resonance peaks of acetylene carbon atoms of 2(4) at $\delta 89.4$ and 88.0. Its spectral pattern largely resembled that of 5-7, confirming that the polymeric product was indeed P1a/2(4) with a molecular structure as shown in Scheme 1.

\section{Thermal properties}

The thermal stabilities of $\mathbf{P 1 a} / \mathbf{2}(\mathrm{m})$ were evaluated by thermogravimetric analysis (TGA). As shown in Fig. 4, all the

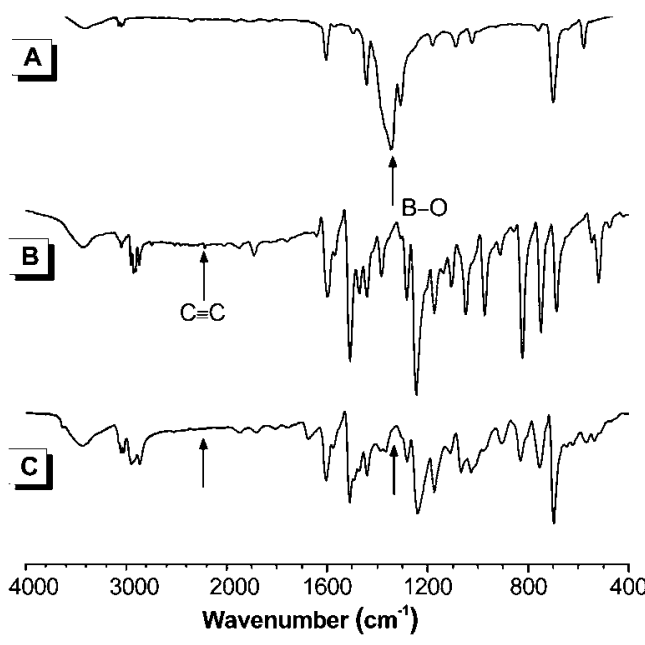

Fig. 1 IR spectra of (A) $\mathbf{1 a}$ and (B) 2(4) and (C) their polymer P1a/2(4). 

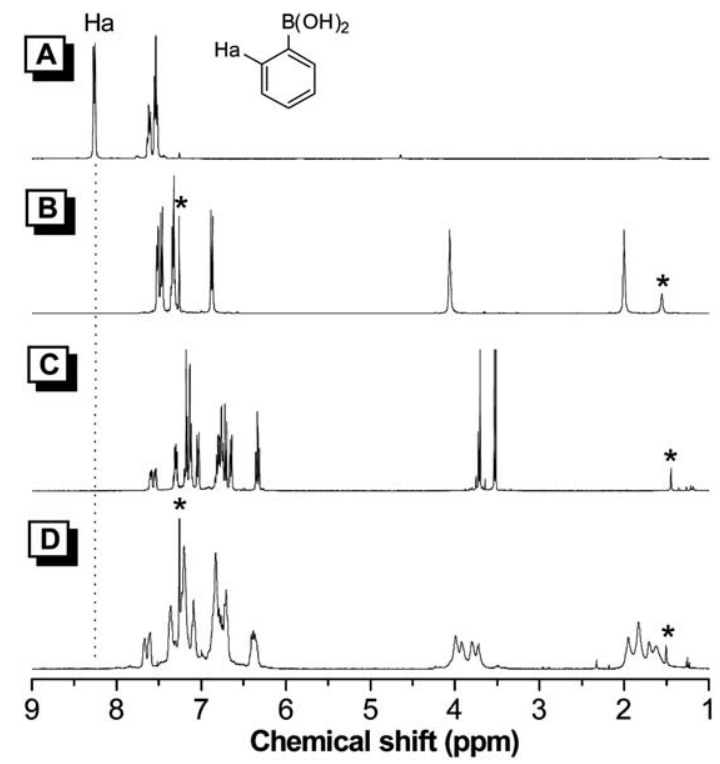

Fig. $2{ }^{1} \mathrm{H}$ NMR spectra of $\mathrm{CDCl}_{3}$ solutions of (A) 1a, (B) 2(4), (C) a mixture of 5-7 and (D) P1a/2(4) (sample taken from Table 3, no. 1). The solvent and water peaks are marked with asterisks.

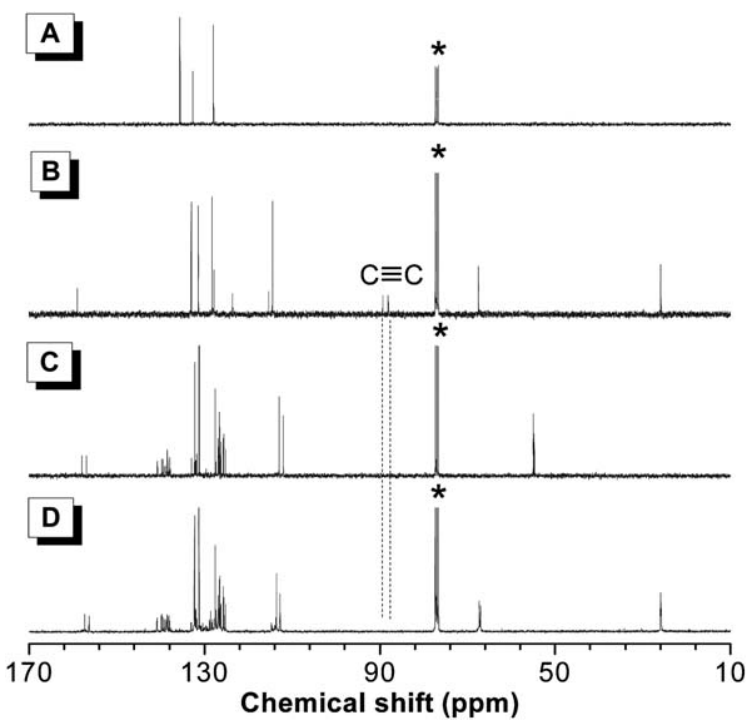

Fig. $3{ }^{13} \mathrm{CNMR}$ spectra of $\mathrm{CDCl}$ s solutions of $(\mathrm{A}) \mathbf{1 a}$, (B) $\mathbf{2}(4),(\mathrm{C})$ a mixture of $\mathbf{5 - 7}$ and (D) P1a/2(4) (sample taken from Table 3, no. 1). The solvent peaks are marked with asterisks.

polymers were thermally stable, losing $5 \%\left(T_{\mathrm{d}}\right)$ of their weight at temperatures higher than $300{ }^{\circ} \mathrm{C}$ under a nitrogen atmosphere.

DSC analysis revealed glass transition temperatures $\left(T_{\mathrm{g}}\right)$ at 95-168 ${ }^{\circ} \mathrm{C}$, suggesting that the polymers enjoyed good morphological stability (Fig. 5). The $T_{\mathrm{g}}$ value was in the order of $\mathrm{P} 1 \mathrm{~b} / 2(6)\left(168{ }^{\circ} \mathrm{C}\right)>\mathrm{P} 1 \mathrm{a} / 2(4)\left(122{ }^{\circ} \mathrm{C}\right)>\mathrm{P} 1 \mathrm{a} / 2(6)\left(109{ }^{\circ} \mathrm{C}\right)>\mathrm{P} 1 \mathrm{a} /$ $2(8)\left(95^{\circ} \mathrm{C}\right)$ and $\mathrm{P} 1 \mathrm{a} / 2(10)\left(98^{\circ} \mathrm{C}\right)$. Such a trend, in some sense, is expected because of the stronger plasticizing effect of the longer alkyl chain, which increases the rotation freedom of the polymer strand and hence reduces their $T_{\mathrm{g}}$. On the other hand, the tetraphenylethene (TPE) unit in P1b/2(6) is rigid, which limits

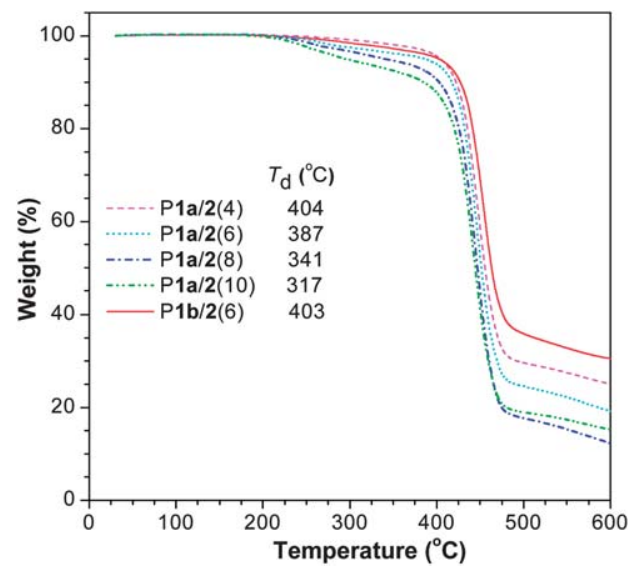

Fig. 4 TGA thermograms of $\mathrm{P} \mathbf{1} / \mathbf{2}(\mathrm{m})$ recorded under a nitrogen atmosphere at a heating rate of $10^{\circ} \mathrm{C} \mathrm{min}^{-1}$.

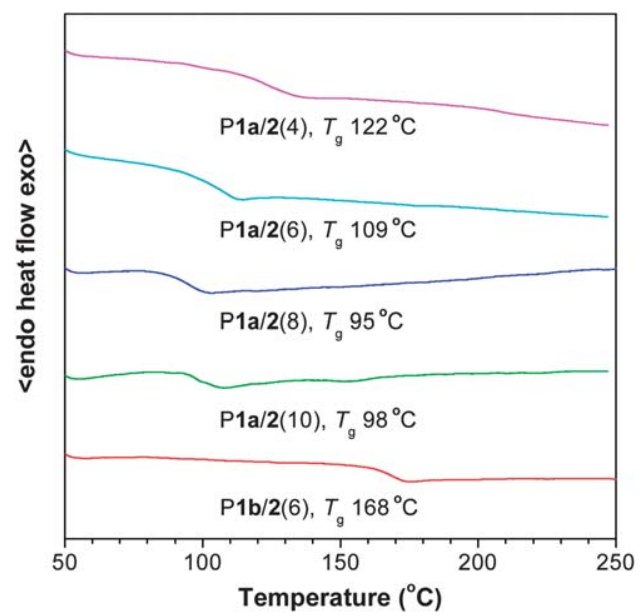

Fig. 5 DSC thermograms of $\mathrm{P} \mathbf{1} / \mathbf{2}(\mathrm{m})$ recorded under a nitrogen atmosphere during the first heating cycle at a scan rate of $10^{\circ} \mathrm{C} \mathrm{min}^{-1}$.

the motion of the polymer strand and hence imparts P1b/2(6) with the highest $T_{\mathrm{g}}$ among the polymers.

\section{Light refraction}

As $\mathbf{P} \mathbf{1} / \mathbf{2}(m)$ contain many polarizable aromatic rings, they may show high refractive indices (RI or $n$ ). The polymers could form light yellow transparent thin films with a thickness of $\sim 4 \mu \mathrm{m}$ by spin-coating their dichloromethane solutions onto a silica substrate. As shown in Fig. 6, all the polymers showed high RI values in a wide wavelength region (400-1600 $\mathrm{nm}$ ). The RI values at $632.8 \mathrm{~nm}$ were all $\geq 1.63$, which were much higher than those of the commercially important optical plastics, such as polyacrylate $(n=1.492)$, polycarbonate $(n=1.581)$ and polystyrene ( $n=1.587)$. Clearly, P1/2 $(m)$ are a class of highly refractive polymers. The magnitude of the RI value at $632.8 \mathrm{~nm}$ was in the order of $\mathrm{P} 1 \mathrm{~b} / 2(6)$ (1.6599) > P1a/2(4) (1.6518) > $\mathrm{P} 1 \mathrm{a} / 2$ (6) (1.6457) > P1a/2(8) (1.6388) > P1a/2(10) (1.6327), which was in good correlation with their aromatic content, ${ }^{17}$ suggesting that the photonic properties of the polymers could be tuned by simply varying the spacer length (Table 4 ). 


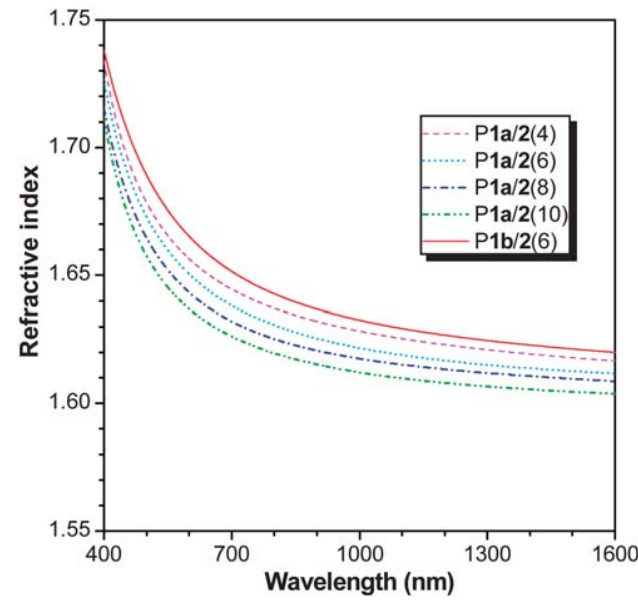

Fig. 6 Wavelength dependence of the refractive index of thin films of P1/2 $(m)$.

Table 4 Refractive indices and chromatic dispersions of P1/2 $(m)^{a}$

\begin{tabular}{lllllll}
\hline No. & Polymer & $n_{632.8}$ & $\nu_{\mathrm{D}}$ & $D$ & $\nu_{\mathrm{D}^{\prime}}$ & $D^{\prime}$ \\
\hline 1 & $\mathrm{P} 1 \mathrm{a} / 2(4)$ & 1.6518 & 19.2686 & 0.0519 & 68.3324 & 0.0146 \\
2 & $\mathrm{P} 1 \mathrm{a} / 2(6)$ & 1.6457 & 18.7605 & 0.0533 & 79.8990 & 0.0125 \\
3 & $\mathrm{P} 1 \mathrm{a} / \mathbf{2}(8)$ & 1.6388 & 19.5757 & 0.0511 & 89.7563 & 0.0111 \\
4 & $\mathrm{P} 1 \mathrm{a} / 2(10)$ & 1.6327 & 20.0514 & 0.0499 & 94.2178 & 0.0106 \\
5 & $\mathrm{P} 1 \mathbf{b} / 2(6)$ & 1.6599 & 17.8588 & 0.0560 & 64.2426 & 0.0156
\end{tabular}

${ }^{a}$ All data were taken from Fig. 6. Abbreviation: $n=$ refractive index (at $632.8 \mathrm{~nm}) . \nu_{\mathrm{D}}=$ Abbé number $=\left(n_{\mathrm{D}}-1\right) /\left(n_{\mathrm{F}}-n_{\mathrm{C}}\right)$, where $n_{\mathrm{D}}, n_{\mathrm{F}}$ and $n_{\mathrm{C}}$ are the RI values at wavelengths of Fraunhofer D, F and $\mathrm{C}$ spectral lines of 589.2, 486.1 and $656.3 \mathrm{~nm}, \nu_{\mathrm{D}^{\prime}}=$ modified Abbé number $=$ $\left(n_{1319}-1\right) /\left(n_{1064}-n_{1550}\right)$, where $n_{1319}, n_{1064}$ and $n_{1550}$ are the RI values at 1319,1064 and $1550 \mathrm{~nm}$, respectively, and $D^{()}=$chromatic dispersion $=1 / \nu_{\mathrm{D}}{ }^{\left({ }^{\prime}\right)}$.

The Abbé number $\left(\nu_{\mathrm{D}}\right)$ of a material is a measure of the variation or dispersion in its RI value with wavelength. A modified Abbé number $\left(\nu_{\mathrm{D}^{\prime}}\right)$ has also been proposed to evaluate the potential application of an optical material. The $\nu_{\mathrm{D}}$ and $\nu^{\prime}$ values of $\mathrm{P1} / 2(\mathrm{~m})$ were in the range of $\sim 17$ to 20 and $\sim 64$ to 94 , corresponding to $D$ and $D^{\prime}$ values of 0.050 to 0.056 and 0.011 to 0.016 , respectively. The high refractivity and low optical dispersion of the polymers make them promising as optical materials.

\section{Photophysical properties}

Our group is interested in studying molecules and polymers with AIE characteristics. These luminogens are non-emissive in dilute solutions but emit intense light in the aggregated state because of the restriction of intramolecular motion. ${ }^{18}$ Since TPE is an archetypical AIE luminogen, P1b/2(6) is anticipated to be AIE-active. This is indeed the case, as suggested by the photographs of its THF solution and THF-water mixture. While the pure THF solution of P1b/2(6) emitted no light upon UV irradiation, weak green emission was observed in a $\mathrm{THF}-\mathrm{H}_{2} \mathrm{O}$ mixture with $30 \%$ water content. The emission became stronger progressively with increasing the water content. To have a quantitative picture, we measured the photoluminescence (PL)
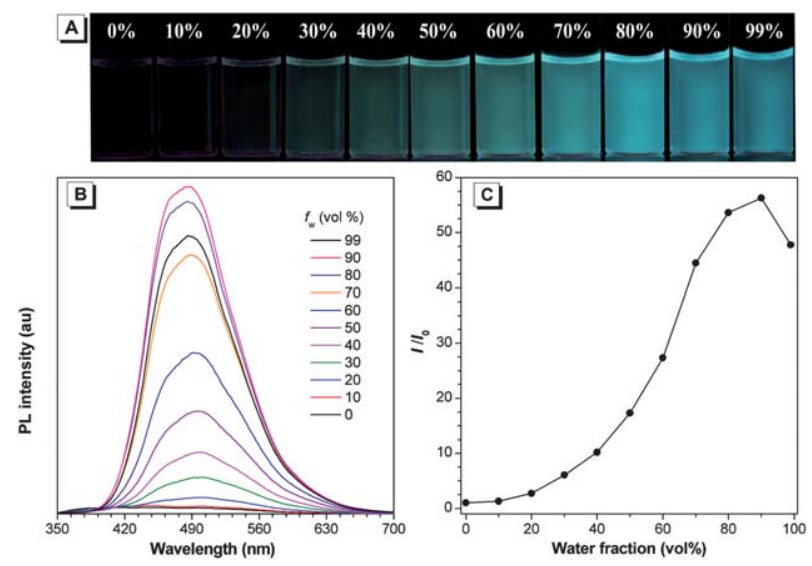

Fig. 7 (A) Photographs of $\mathrm{P} \mathbf{1} \mathbf{b} / \mathbf{2}(6)$ in $\mathrm{THF}-\mathrm{H}_{2} \mathrm{O}$ mixtures with different water fractions $\left(f_{\mathrm{w}}\right)$ taken under $365 \mathrm{~nm}$ UV irradiation from a hand-held UV lamp. (B) PL spectra of P1b/2(6) in THF and THF-water mixtures. Concentration: $10 \mu \mathrm{M}$ and excitation wavelength: $327 \mathrm{~nm}$. (C) Plot of relative PL intensity $\left(I / I_{0}\right)$ versus the solvent composition of THF-water mixture of $\mathrm{P} \mathbf{1 b} / \mathbf{2}(6)$.

of $\mathrm{P} \mathbf{1 b} / 2(6)$ in the solution and aggregated states using a spectrometer. Nearly no signal was recorded in THF solution (Fig. 7B). At $20 \%$ water content, a weak broad peak appeared at $\sim 500 \mathrm{~nm}$. The spectral pattern remained unchanged but the PL intensity increased gradually with an increase in the water content. Because of the immiscibility of the hydrophobic polymer with the hydrophilic medium, the chains of P1b/2(6) must have been aggregated in aqueous mixtures with high water contents. Evidently, P1b/2(6) is AIE-active. In the solution state, the active rotation of the phenyl rings of the TPE unit effectively consumes the energy of the excitons, which renders the polymer weakly emissive in the solution. In the aggregated state, such motion is restricted, which blocks the nonradiative relaxation channel and populates the radiative excitons, thus turning P1b/ $2(6)$ into a strong emitter. The fluorescence quantum yield $\left(\Phi_{\mathrm{F}}\right)$ value of $\mathrm{P} 1 \mathrm{~b} / 2(6)$ in THF solution was merely $0.18 \%$, suggesting that the polymer was genuinely dissolved in a good solvent. The $\Phi_{\mathrm{F}}$ value in $90 \%$ aqueous mixture was much higher $(4.15 \%)$, being 23-fold higher than that in THF solution. Even higher $\Phi_{\mathrm{F}}$ value $(9.45 \%)$ was observed in the solid powder of $\mathrm{P} \mathbf{1 b} / \mathbf{2}(6)$

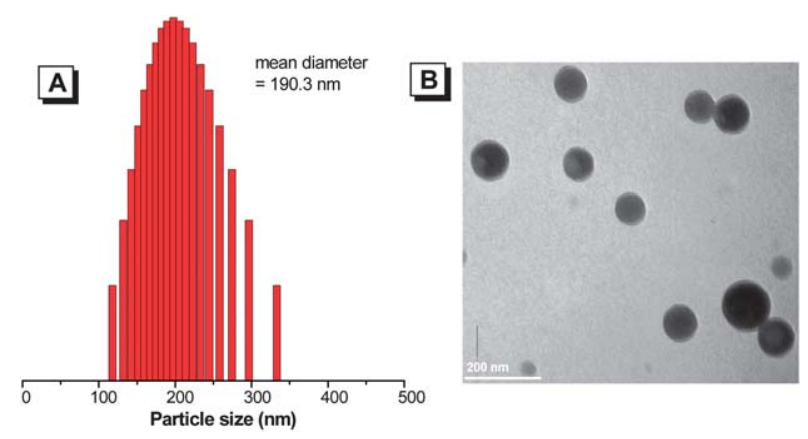

Fig. 8 (A) Size distribution of nanoparticles of $\mathrm{P} \mathbf{1 b} / \mathbf{2}(6)$ suspended in $90 \%$ aqueous mixture. (B) TEM image of nanoparticles of P1b/2(6) formed in $90 \%$ aqueous mixture. Concentration: $10 \mu \mathrm{M}$. 
determined by a calibrated integrating sphere, presumably due to the tighter aggregation of the polymer chains.

It is noteworthy that the aqueous mixture of $P 1 \mathbf{b} / 2(6)$ is homogeneous without precipitates even at a water content of $90 \%$, revealing that the particles are of nano-dimension. To prove this, we analyzed the particle size of P1b/2(6) in $90 \%$ aqueous mixture using a zeta potential analyzer (Fig. 8A), from which particles with a mean diameter of $\sim 190 \mathrm{~nm}$ and a polydispersity of 0.12 were deduced. The morphology of the nanoparticles was studied using a transmission electron microscope (TEM). The sample was prepared by drop-casting a solution of P1b/2(6) (90\% aqueous mixture) onto a copper grid. As shown in Fig. 8B, the polymer nanoparticles were spherical in shape. The mean diameter of the nanoparticles (70-130 nm) analyzed using a TEM was much smaller than that determined using a zeta potential analyzer, probably due to the shrinking of the sample when transformed from the solution to the dry state.

\section{Explosive detection}

Sensors based on fluorescent polymers have attracted much attention due to their superior sensitivity to analytes compared with their low molar mass congeners. Generally, intrinsic autoaggregation of conventional conjugated polymers and/or their analyte-induced aggregation causes self-quenching problems that greatly reduce their sensing performance. However, aggregation is beneficial to the emission of P1b/2(6) with AIE characteristic, which prompts us to explore its potential application as a chemosensor for detecting explosives because of the involved potential anti-terrorism implication. ${ }^{19}$ 2,4,6-Trinitrophenol (picric acid, PA) is used as a model compound because it is commercially available, while nanoaggregates of $\mathrm{P1b} / 2(6)$ in a THF-water mixture with $90 \%$ water content were utilized as explosive probes. As shown in Fig. 9A, the emission of P1b/2(6) was weakened when PA was gradually added into the aqueous mixture. The fluorescence quenching could be clearly discerned at a PA concentration as low as $10 \mu \mathrm{M}$. At a PA concentration of $0.8 \mathrm{mM}$, virtually no light can be detected by the spectrofluorometer. The Lewis acid-base interactions between the electron-rich polymer chains and the electron-
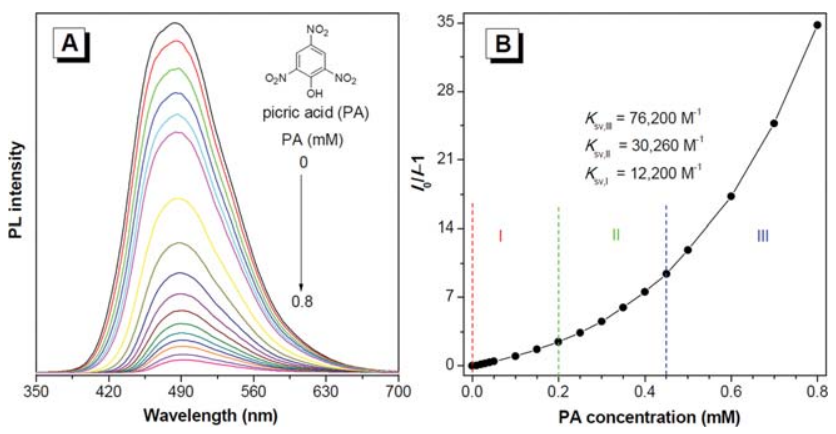

Fig. 9 (A) PL spectra of P1b/2(6) in a THF-water mixture with $90 \%$ water fraction containing different amounts of picric acid (PA). (B) Stern-Volmer plot of $\left(I_{0} / I-1\right)$ values versus PA concentrations in $90 \%$ aqueous mixture of $\mathrm{P} \mathbf{1 b} / \mathbf{2}(6)$. $I_{0}=$ peak intensity at $[\mathrm{PA}]=0 \mathrm{M}$. Concentration: $10 \mu \mathrm{M}$ and excitation wavelength: $327 \mathrm{~nm}$. Inset: (A) chemical structure of PA.

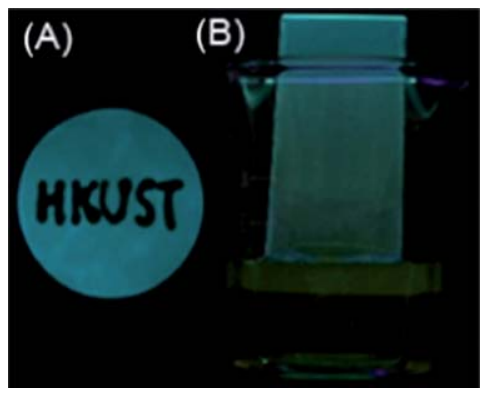

Fig. 10 (A) Fluorescent image of $\mathrm{P} \mathbf{1 b} / \mathbf{2}(6)$ deposited on a filter paper. The letters "HKUST" were written by dropping aliquots of a PA solution on the filter paper using a capillary tube. (B) A fluorescent film of P1 b/2(6) was fabricated on a glass substrate by static-casting and its fluorescence was completely quenched after dipping into the PA solution.

deficient PA molecules may play a key role in the quenching process. The Stern-Volmer plot of relative PL intensity $\left(I_{0} / I-1\right)$ versus the PA concentration gave an upward bending curve instead of a linear line (Fig. 9B), showing a superamplified quenching effect. ${ }^{20}$ Large quenching constants up to $76200 \mathrm{M}^{-1}$ were deduced from the plot, which were higher than those of polysiloles and polygermoles reported previously (6710$11000 \mathrm{M}^{-1}$ ) in solutions. ${ }^{21}$ The nanoaggregates of $\mathrm{P} \mathbf{1 b} / \mathbf{2}(6)$ have more cavities to bind with more quencher molecules and provide additional pathways for interchain diffusion of excitons, thus making the quenching a highly efficient process.

In addition to the "wet" measurement, we also tested whether the PA detection could work in the solid state. The polymer was adsorbed onto a filter paper. Letters of "HKUST" were then written by dropping aliquots of a PA solution on the filter paper using a capillary tube. Upon photoexcitation, the letters emitted no light due to the emission quenching by the PA molecules, while the remaining parts showed intense blue PL (Fig. 10A). In addition, P1b/2(6) could form a good solid film on a glass substrate by static-casting, whose strong PL was completely quenched after dipping into an aqueous solution of PA $\left(50 \mu \mathrm{g} \mathrm{mL}^{-1}\right)$ (Fig. 10B). Both experiments thus demonstrate the prototype devices using AIE-active P1b/2(6) for detecting explosives in real-world applications.

\section{Conclusions}

In this work, we developed a new stoichiometric imbalancepromoted polymerization route for the synthesis of functional polymers. Oxidative polycoupling of arylboronic acids and internal diynes was promoted by $\left[\mathrm{Cp}^{*} \mathrm{RhCl}_{2}\right]_{2}$ and oxidants in DMF for $2 \mathrm{~h}$, generating polymers with highly substituted naphthalene rings in satisfactory yields with moderate molecular weights. The polymers were completely soluble, filmforming, and thermally and morphologically stable. Thin solid films of the polymers exhibited high refractive indices $(\mathrm{RI}=$ 1.7414-1.6038) in a wide wavelength region of 400-1600 nm. The polymer containing TPE unit showed an unusual AIE characteristic and its nanoaggregates worked as sensitive chemosensors for superamplified detection of explosives. 


\section{Experimental section}

\section{General information}

Tetrahydrofuran (THF) was distilled under a nitrogen atmosphere from sodium benzophenone ketyl immediately prior to use. Dimethylformamide (DMF) was distilled over calcium hydride and stored over molecular sieves. The rhodium complex $\left[\mathrm{RhCp}^{*} \mathrm{Cl}_{2}\right]_{2},{ }^{22}$ 4-(1,2,2-triphenylvinyl)phenylboronic acid (1b), ${ }^{13}$ 4-hydroxyldiphenylacetylene $(3)^{\mathbf{1 4}}$ and 4-methoxydiphenylacetylene $(\mathbf{4})^{15}$ were prepared according to the literature methods. Other chemicals and reagents were all purchased from Aldrich and used as received without further purification.

Weight- $\left(M_{\mathrm{w}}\right)$ and number-average $\left(M_{\mathrm{n}}\right)$ molecular weights and polydispersities $\left(M_{\mathrm{w}} / M_{\mathrm{n}}\right)$ of the polymers were estimated by a Waters Gel Permeation Chromatography (GPC) system equipped with a Waters 515 HPLC pump, a set of Styragel columns (HT3, HT4 and HT6; molecular weight range $10^{2}$ to $10^{7}$ ), a column temperature controller, a Waters 486 wavelength-tunable UV-vis detector, a Waters 2414 differential refractometer and a Waters 2475 fluorescence detector. The polymers were dissolved in THF $\left(\sim 1 \mathrm{mg} \mathrm{mL} \mathrm{mL}^{-1}\right)$ and filtered through $0.45 \mu \mathrm{m}$ PTFE syringe-type filters before being injected into the GPC system. THF was used as the eluent at a flow rate of $1.0 \mathrm{~mL} \mathrm{~min}^{-1}$. The column temperature was maintained at $40{ }^{\circ} \mathrm{C}$ and the working wavelength of the UV-vis detector was set at $254 \mathrm{~nm}$. A set of monodispersed polystyrene standards (Waters) covering the molecular weight range of $10^{3}$ to $10^{7}$ were used for the molecular weight calibration. IR spectra were recorded on a Perkin-Elmer 16 PC FTIR spectrophotometer. ${ }^{1} \mathrm{H}$ and ${ }^{13} \mathrm{C}$ NMR spectra were measured on Bruker ARX 400 NMR spectrometers using chloroform-d as the solvent. High resolution mass spectra (HRMS) were recorded on a GCT Premier CAB 048 mass spectrometer operated in MALDI-TOF mode. Thermogravimetric analyses (TGA) were conducted under a nitrogen atmosphere on a Perkin-Elmer TGA 7 analyzer at a heating rate of $10{ }^{\circ} \mathrm{C} \min ^{-1}$. The thermal transitions were investigated by differential scanning calorimetry (DSC) using a TA Instruments DSC Q1000 at a heating rate of $10{ }^{\circ} \mathrm{C} \mathrm{min}^{-1}$. Particle sizes of the polymer aggregates in THF-water mixtures were measured on a BeCoulter Delsa 440SX Zeta potential analyzer. The morphology of the polymer nanoaggregates was investigated by transmission electron microscopy (JEM-2010F, JEOL, Japan).

\section{Monomer synthesis}

Monomers $2(\mathrm{~m})$ were prepared according to a modified literature method. ${ }^{15}$ A typical procedure for the preparation of $4,4^{\prime}$ (1,4-butylenedioxy) bis(diphenylacetylene) 2 (4) is given below as an example.

Into a $100 \mathrm{~mL}$ round-bottom flask containing 3 (1.94 g, $10 \mathrm{mmol})$ and $\mathrm{KOH}(0.56 \mathrm{~g}, 10 \mathrm{mmol})$ were added $30 \mathrm{~mL}$ of $n$-butanol and $1.07 \mathrm{~g}$ (5 mmol) of 1,4-dibromobutane. The mixture was heated to reflux for $4 \mathrm{~h}$. After being cooled to room temperature, the reaction mixture was poured into water $(200 \mathrm{~mL})$ and extracted with $\mathrm{CH}_{2} \mathrm{C1}_{2}(60 \mathrm{~mL} \times 3)$. The organic layers were combined and dried over $\mathrm{Na}_{2} \mathrm{SO}_{4}$. After filtration and solvent evaporation, the crude product was purified by silica gel column chromatography using hexane/ethyl acetate as the eluent. White solid; yield $80 \%(1.77 \mathrm{~g})$. IR (KBr), $\nu\left(\mathrm{cm}^{-1}\right)$ : 1283, 1246, 1175 (C-O stretching). ${ }^{1} \mathrm{H}$ NMR $\left(\mathrm{CDCl}_{3}, 400 \mathrm{MHz}\right), \delta$ (ppm): 7.52-7.51 (m, 4H), $7.46(\mathrm{~d}, J=8.8 \mathrm{~Hz}, 4 \mathrm{H}), 7.36-7.31(\mathrm{~m}$, $6 \mathrm{H}), 6.87$ (d, $J=8.8 \mathrm{~Hz}, 4 \mathrm{H}), 4.06$ (br s, $4 \mathrm{H}), 2.00$ (br s, $4 \mathrm{H}) .{ }^{13} \mathrm{C}$ NMR ( $\left.\mathrm{CDCl}_{3}, 100 \mathrm{MHz}\right), \delta$ (ppm): 159.0, 133.0, 131.4, 128.3, 127.9, 123.4 , 115.3, 114.5, 89.4, 88.0, 67.5, 25.9. HRMS (MALDITOF): $m / z 442.1927\left(\mathrm{M}^{+}\right.$, calcd 442.1933).

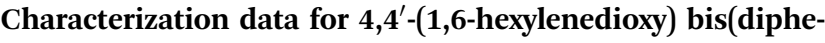
nylacetylene) 2(6). White solid; yield $85 \%$ (2.0 g). IR ( $\mathrm{KBr})$, $\nu\left(\mathrm{cm}^{-1}\right):$ 1285, 1246, 1175 (C-O stretching). ${ }^{1} \mathrm{H}$ NMR $\left(\mathrm{CDCl}_{3}\right.$, $400 \mathrm{MHz}), \delta(\mathrm{ppm}): 7.52-7.50(\mathrm{~m}, 4 \mathrm{H}), 7.46(\mathrm{~d}, J=8.4 \mathrm{~Hz}, 4 \mathrm{H})$, $7.34-7.32(\mathrm{~m}, 6 \mathrm{H}), 6.87$ (d, $J=8.4 \mathrm{~Hz}, 4 \mathrm{H}), 3.99(\mathrm{t}, J=6.4 \mathrm{~Hz}$, $4 \mathrm{H}), 1.84-1.76(\mathrm{~m}, 4 \mathrm{H}), 1.55-1.45(\mathrm{~m}, 4 \mathrm{H}) .{ }^{13} \mathrm{C} \mathrm{NMR}\left(\mathrm{CDCl}_{3}\right.$, $100 \mathrm{MHz}$ ), $\delta$ (TMS, ppm): 159.1, 133.0, 131.4, 128.3, 127.9, 123.6, 115.1, 114.5, 89.4, 88.0, 67.8, 29.1, 25.8. HRMS (MALDI-TOF): $\mathrm{m} / \mathrm{z} 470.2242\left(\mathrm{M}^{+}\right.$, calcd 470.2246).

Characterization data for $\mathbf{4 , 4}$-(1,8-octylenedioxy) bis(diphenylacetylene) 2(8). White solid; yield $88 \%$ (2.19 g). IR ( $\mathrm{KBr}), \nu$ $\left(\mathrm{cm}^{-1}\right): 1284,1247,1173$ (C-O stretching). ${ }^{1} \mathrm{H}$ NMR $\left(\mathrm{CDCl}_{3}\right.$, $400 \mathrm{MHz}), \delta(\mathrm{ppm}): 7.53-7.51(\mathrm{~m}, 4 \mathrm{H}), 7.46(\mathrm{~d}, J=8.8 \mathrm{~Hz}, 4 \mathrm{H})$, $7.37-7.32(\mathrm{~m}, 6 \mathrm{H}), 6.87$ (d, $J=8.8 \mathrm{~Hz}, 4 \mathrm{H}), 3.97$ (t, $J=6.4 \mathrm{~Hz}$, $4 \mathrm{H}), 1.85-1.76(\mathrm{~m}, 4 \mathrm{H}), 1.56-1.41(\mathrm{~m}, 8 \mathrm{H}) .{ }^{13} \mathrm{C} \mathrm{NMR}\left(\mathrm{CDCl}_{3}\right.$, $100 \mathrm{MHz}), \delta$ (ppm): 159.2, 133.0, 131.4, 128.3, 127.9, 123.6, 115.1, 114.5, 89.4, 88.0, 68.0, 29.3, 29.2, 25.9. HRMS (MALDITOF): $m / z 498.2540\left(\mathbf{M}^{+}\right.$, calcd 498.2559).

Characterization data for $4, \mathbf{4}^{\prime}-\mathbf{( 1 , 1 0 - d e c y l e n e d i o x y )}$ bis(diphenylacetylene) 2(10). White solid; yield 81\% (2.13 g). IR (KBr), $\nu\left(\mathrm{cm}^{-1}\right):$ 1284, 1247, 1172 (C-O stretching). ${ }^{1} \mathrm{H} \mathrm{NMR}\left(\mathrm{CDCl}_{3}\right.$, $400 \mathrm{MHz}), \delta$ (ppm): 7.52-7.50 (m, 4H), $7.48(\mathrm{~d}, J=8.8 \mathrm{~Hz}, 4 \mathrm{H})$, $7.35-7.31(\mathrm{~m}, 6 \mathrm{H}), 6.87$ (d, $J=8.8 \mathrm{~Hz}, 4 \mathrm{H}), 3.97$ (t, $J=6.4 \mathrm{~Hz}$, $4 \mathrm{H}), 1.81-1.75(\mathrm{~m}, 4 \mathrm{H}), 1.48-1.34(\mathrm{~m}, 12 \mathrm{H}) .{ }^{13} \mathrm{C} \mathrm{NMR}\left(\mathrm{CDCl}_{3}\right.$, $100 \mathrm{MHz}), \delta$ (ppm): 159.2, 133.0, 131.4, 128.3, 127.9, 123.6, $115.1,114.5,89.4,87.9,68.0,29.4,29.3,29.2$, 26.0. HRMS (MALDI-TOF): $m / z 526.2885\left(\mathrm{M}^{+}\right.$, calcd 526.2872).

\section{Synthesis of model compounds}

To a $15 \mathrm{~mL}$ Schlenk tube with a three-way stopcock on the sidearm were added $\left[\mathrm{RhCp}^{*} \mathrm{Cl}_{2}\right]_{2}(3.09 \mathrm{mg}, 0.005 \mathrm{mmol})$, AgOTs (55.6 mg, $0.20 \mathrm{mmol}), \mathbf{1 a}(24.4 \mathrm{mg}, 0.20 \mathrm{mmol})$ and 4 (41.6 mg, $0.20 \mathrm{mmol}$ ) under a nitrogen atmosphere. Freshly dried DMF $(1.0 \mathrm{~mL})$ was then injected into the tube using a hypodermic syringe. The resulting mixture was stirred at $100{ }^{\circ} \mathrm{C}$ under a nitrogen atmosphere for $2 \mathrm{~h}$. The reaction mixture was then cooled to room temperature and extracted with ethyl acetate $(60 \mathrm{~mL} \times 3)$. The organic layer was washed by water $(100 \mathrm{~mL} \times 3)$ and dried over $\mathrm{Na}_{2} \mathrm{SO}_{4}$. After purification by silica gel column chromatography using hexane-ethyl acetate mixture $(50: 1, \mathrm{v} / \mathrm{v})$ as the eluent, a yellow solid of a mixture of 5-7 (40.3 mg, 82\%) was obtained. IR (KBr), $\nu\left(\mathrm{cm}^{-1}\right)$ : 1510, 1243, 1174, 1031 (C-O stretching). ${ }^{1} \mathrm{H} \mathrm{NMR}\left(\mathrm{CDCl}_{3}\right.$, $400 \mathrm{MHz}$ ), $\delta$ (ppm): 7.60-6.33 (aromatic protons), 3.70, 3.54, $3.52\left(\mathrm{OCH}_{3}\right.$ protons). ${ }^{13} \mathrm{C} \mathrm{NMR}\left(\mathrm{CDCl}_{3}, 100 \mathrm{MHz}\right), \delta(\mathrm{ppm})$ : 157.9, 156.9, 140.8-112.0, 55.0, 54.8. HRMS (MALDI-TOF): $m / z$ 492.2090 $\left(\mathrm{M}^{+}\right.$, calcd 492.2089). 


\section{Polymerization}

All the polymerization reactions were carried out under a nitrogen atmosphere using a standard Schlenk technique. A typical procedure for the polymerization of $\mathbf{1 a}$ and 2(4) is given below as an example.

To a $15 \mathrm{~mL}$ Schlenk tube with a three-way stopcock on the sidearm were added $\left[\mathrm{RhCp}^{*} \mathrm{Cl}_{2}\right]_{2}(3.09 \mathrm{mg}, 0.005 \mathrm{mmol})$, AgOTs (55.6 mg, $0.20 \mathrm{mmol}), 1 \mathrm{a}(24.4 \mathrm{mg}, 0.20 \mathrm{mmol}$ ) and 2(4) (44.2 mg, $0.10 \mathrm{mmol}$ ) under a nitrogen atmosphere. Freshly distilled DMF $(1.0 \mathrm{~mL})$ was then injected into the tube using a hypodermic syringe. The resulting mixture was stirred at $100{ }^{\circ} \mathrm{C}$ under a nitrogen atmosphere for $2 \mathrm{~h}$. The solution was added dropwise into $200 \mathrm{~mL}$ of methanol via a cotton filter under stirring. The precipitate was allowed to stand overnight and then collected by filtration. The polymer was washed with methanol and dried under vacuum at room temperature to a constant weight. Light yellow powder of polymer P1a/2(4) was obtained in $83 \%$ yield. $M_{\mathrm{w}}$ 9200; $M_{\mathrm{w}} / M_{\mathrm{n}} 1.9$ (Table 3, no. 1). IR $(\mathrm{KBr}), \nu\left(\mathrm{cm}^{-1}\right): 1281,1239,1173$ (C-O stretching). ${ }^{1} \mathrm{H}$ NMR $\left(\mathrm{CDCl}_{3}, 400 \mathrm{MHz}\right), \delta$ (ppm): 7.77-6.36 (aromatic protons), 3.99$3.72\left(\mathrm{OCH}_{2}\right.$ protons $), 1.95-1.62 .{ }^{13} \mathrm{C} \mathrm{NMR}\left(\mathrm{CDCl}_{3}, 100 \mathrm{MHz}\right), \delta$ (ppm): 157.3, 156.3, 140.8-112.7, 67.3, 25.9.

$P 1 a / 2(6)$ : light yellow powder; yield 80\%. $M_{\mathrm{w}} 10500 ; M_{\mathrm{w}} / M_{\mathrm{n}}$ 2.0 (GPC, polystyrene calibration). IR (KBr), $\nu\left(\mathrm{cm}^{-1}\right): 1281$, 1239, 1173 (C-O stretching). ${ }^{1} \mathrm{H}$ NMR $\left(\mathrm{CDCl}_{3}, 400 \mathrm{MHz}\right), \delta$ (ppm): 7.80-6.50 (aromatic protons), 4.05-3.86 ( $\mathrm{OCH}_{2}$ protons), 1.98-1.65. ${ }^{13} \mathrm{C} \mathrm{NMR}\left(\mathrm{CDCl}_{3}, 100 \mathrm{MHz}\right), \delta$ (ppm): 156.5, 140.9, 139.9-112.8, 67.7, 29.4, 25.9.

$P 1 a / 2(8)$ : light yellow powder; yield 78\%. $M_{\mathrm{w}} 9100 ; M_{\mathrm{w}} / M_{\mathrm{n}} 2.0$ (GPC, polystyrene calibration). IR (KBr), $\nu\left(\mathrm{cm}^{-1}\right): 1281,1241$, 1171 (C-O stretching). ${ }^{1} \mathrm{H}$ NMR $\left(\mathrm{CDCl}_{3}, 400 \mathrm{MHz}\right), \delta(\mathrm{ppm})$ : 7.69-6.41 (aromatic protons), 3.93-3.74 $\left(\mathrm{OCH}_{2}\right.$ protons), 1.781.36. ${ }^{13} \mathrm{C} \mathrm{NMR}\left(\mathrm{CDCl}_{3}, 100 \mathrm{MHz}\right), \delta$ (ppm): 157.5, 156.5, 140.9112.7, 67.8, 29.3, 26.0.

$P 1 a / 2(10)$ : light yellow powder; yield $62 \% . M_{\mathrm{w}} 6300 ; M_{\mathrm{w}} / M_{\mathrm{n}}$ 1.8 (GPC, polystyrene calibration). IR ( $\mathrm{KBr}), \nu\left(\mathrm{cm}^{-1}\right): 1282$, 1242, 1172 (C-O stretching). ${ }^{1} \mathrm{H}$ NMR $\left(\mathrm{CDCl}_{3}, 400 \mathrm{MHz}\right), \delta$ (ppm): 7.77-6.36 (aromatic protons), 3.99-3.72 ( $\mathrm{OCH}_{2}$ protons), 1.95-1.62. ${ }^{13} \mathrm{C} \mathrm{NMR}\left(\mathrm{CDCl}_{3}, 100 \mathrm{MHz}\right), \delta$ (ppm): 157.5, 156.5, 140.9-112.7, 67.9, 34.2, 30.3, 29.5, 26.0.

$P 1 b / 2(6)$ : brown powder; yield 86\%. $M_{\mathrm{w}} 11600 ; M_{\mathrm{w}} / M_{\mathrm{n}} 2.1$ (GPC, polystyrene calibration). IR (KBr), $\nu\left(\mathrm{cm}^{-1}\right): 1282,1239$, 1172 (C-O stretching). ${ }^{1} \mathrm{H}$ NMR $\left(\mathrm{CDCl}_{3}, 400 \mathrm{MHz}\right), \delta$ (ppm): 7.49-6.36 (aromatic protons), 3.87-3.71 ( $\mathrm{OCH}_{2}$ protons), 1.781.36. ${ }^{13} \mathrm{C} \mathrm{NMR}\left(\mathrm{CDCl}_{3}, 100 \mathrm{MHz}\right), \delta(\mathrm{ppm}): 156.7,157.0,156.4$, 143.9-112.7, 67.6, 29.2, 25.9.

\section{Acknowledgements}

The work reported in this paper was partially supported by the National Science Foundation of China (20974028), the RPC and SRFI Grants of HKUST (RPC10SC13, RPC11SC09 and SRFI11SC03PG), the Research Grants Council of Hong Kong (604711, 602212, HKUST2/CRF/10 and N_HKUST620/11), the Innovation and Technology Commission (ITCPD/17-9) and the University Grants Committee of Hong Kong (AoE/P-03/08). B. Z.
Tang thanks the support of the Guangdong Innovative Research Team Program.

\section{References}

1 (a) P. J. Flory, Principles of Polymer Chemistry, Cornell University Press, Ithaca, NY, 1953; (b) G. Odian, Principle of Polymerization, Wiley, New York, 3rd edn, 1991, ch. 2.

2 N. Nishioka, S. Hayashi and T. Koizumi, Angew. Chem., Int. Ed., 2012, 51, 3682-3685.

3 (a) K. Wakabayashi, S. I. Kohama, S. Yamazaki and K. Kimura, Macromolecules, 2008, 41, 1168-1174; (b) D. Zhao and K. Yue, Macromolecules, 2008, 41, 4029-4036; (c) D. Zhao and J. S. Moore, J. Am. Chem. Soc., 2003, 125, 16294-16299; (d) K. Kimura, S. I. Kohama and Y. Yamashita, Macromolecules, 2003, 36, 5043-5046; (e) K. Kimura, S. I. Kohama and Y. Yamashita, Macromolecules, 2002, 35, 7545-7552; (f) S. I. Kohama, K. Kimura and Y. Yamashita, J. Polym. Sci., Part A: Polym. Chem., 2005, 43, 1757-1766.

4 (a) N. Nomura, K. Tsurugi and M. Okada, Angew. Chem., Int. Ed., 2001, 40, 1932-1935; (b) N. Nomura, K. Tsurugi, T. V. RajanBabu and T. Kondo, J. Am. Chem. Soc., 2004, 126, 5354-5355.

5 T. Takemura, K. Sugie, H. Nishino, S. Kawabata and T. Koizumi, J. Polym. Sci., Part A: Polym. Chem., 2008, 46, 2250-2261.

6 N. Kihara, S. Komatsu, T. Takata and T. Endo, Macromolecules, 1999, 32, 4776-4783.

7 H. Iimori, Y. Shibasaki, S. Ando and M. Ueda, Macromol. Symp., 2003, 199, 23-35.

8 T. Dutta, K. B. Woody and M. D. Watson, J. Am. Chem. Soc., 2008, 130, 452-453.

9 (a) V. C. Sundar, J. Zaumseil, V. Podzorov, E. Menard, R. L. Willett, T. Someya, M. E. Gershenson and J. A. Rogers, Science, 2004, 303, 1644-1646; (b) J. Feng, X. Chen, Q. Han, H. Wang, P. Lu and Y. Wang, J. Lumin., 2011, 131, 2775-2783; (c) M. S. Goncalves, Chem. Rev., 2009, 109, 190-212; (d) S. Li, J. Xiang, X. Mei and C. Xu, Tetrahedron Lett., 2008, 49, 1690-1693.

10 (a) G. Dyker, Handbook of $C-H$ Transformations: Applications in Organic Synthesis, Wiley-VCH, Weinheim, 2005; (b) J. Q. Yu and Z. J. Shi, $C-H$ Activation, Springer, Berlin, Germany, 2010.

11 (a) T. Fukutani, K. Hirano, T. Satoh and M. Miura, J. Org. Chem., 2011, 76, 2867-2874; (b) T. Fukutani, K. Hirano, T. Satoh and M. Miura, Org. Lett., 2009, 11, 5198-5201 and references cited therein; (c) H. Horiguchi, K. Hirano, T. Satoh and M. Miura, Adv. Synth. Catal., 2009, 351, 14311436; (d) T. Uto, M. Shimizu, K. Ueura, H. Tsurugi, T. Satoh and M. Miura, J. Org. Chem., 2008, 73, 298-300; (e) Y.-T. Wu, K.-H. Huang, C.-C. Shin and T.-C. Wu, Chem.Eur. J., 2008, 14, 6697-6703; (f) J.-C. Hsieh and C.-H. Cheng, Chem. Commun., 2008, 2992-2994; $(g)$ K. Ueura, T. Satoh and M. Miura, J. Org. Chem., 2007, 72, 5362-5367; (h) Y. Harada, J. Nakanishi, H. Fujihara, M. Tobisu, Y. Fukumoto and N. Chatani, J. Am. Chem. Soc., 
2007, 129, 5766-5771; (i) S. Kawasaki, T. Satoh, M. Miura and M. Nomura, J. Org. Chem., 2003, 68, 6836-6838; (j) T. Yasukawa, T. Satoh, M. Miura and M. Nomura, J. Am. Chem. Soc., 2002, 124, 12680-12681; (k) D. Pena, D. Perez, E. Guitian and L. Castedo, J. Am. Chem. Soc., 1999, 121, 5827-5828.

12 (a) J. L. Liu, J. W. Y. Lam and B. Z. Tang, Chem. Rev., 2009, 109, 5799-5867; (b) A. Qin, J. W. Y. Lam and B. Z. Tang, Chem. Soc. Rev., 2010, 39, 2522-2544; (c) J. Liu, J. W. Y. Lam and B. Z. Tang, Chem. Rev., 2009, 109, 57995867; (d) J. W. Y. Lam and B. Z. Tang, Acc. Chem. Res., 2005, 38, 745-754; (e) A. Qin, J. W. Y. Lam and B. Z. Tang, Prog. Polym. Sci., 2012, 37, 182-209; (f) J. Liu, C. Deng, N.-W. Tseng, C. Y. K. Chan, Y. Yue, J. C. Y. Ng, J. W. Y. Lam, J. Wang, Y. Hong, H. H. Y. Sung, I. D. Williams and B. Z. Tang, Chem. Sci., 2011, 2, 1850-1859.

13 Z. J. Zhao, S. M. Chen, J. W. Y. Lam, P. Lu, Y. C. Zhong, K. S. Wong, H. S. Kwok and B. Z. Tang, Chem. Commun., 2010, 46, 2221-2223.

14 C. K. W. Jim, J. W. Y. Lam, C. W. T. Leung, A. Qin, F. Mahtab and B. Z. Tang, Macromolecules, 2011, 44, 2427-2437.

15 J. Neigenfink, A. Martin, V. Wendel and W. Abraham, J. Prakt. Chem./Chem.-Ztg., 1998, 340, 632-641.

16 (a) A. R. Cruz, M. C. G. Hernandez, M. T. Guzmán-Gutiérrez, M. G. Zolotukhin, S. Fomine, S. L. Morales, H. Kricheldorf,
E. S. Wilks, J. Cárdenas and M. Salmón, Macromolecules, 2012, 45, 6774-6780; (b) H. R. Kricheldorf, M. G. Zolotukhin and J. Cardenas, Macromol. Rapid Commun., 2012, DOI: 10.1002/marc.201200345.

17 J.-g. Liu and M. Ueda, J. Mater. Chem., 2009, 19, 89078919.

18 (a) Y. Hong, J. W. Lam and B. Z. Tang, Chem. Soc. Rev., 2011, 40, 5361-5388; (b) Y. Hong, J. W. Y. Lam and B. Z. Tang, Chem. Commun., 2009, 4332; (c) R. Hu, J. W. Y. Lam, J. Liu, H. H. Y. Sung, I. D. Williams, Z. Yue, K. S. Wong, M. M. F. Yuen and B. Z. Tang, Polym. Chem., 2012, 3, 1481; (d) H. Li, J. Wang, J. Z. Sun, R. Hu, A. Qin and B. Z. Tang, Polym. Chem., 2012, 3, 1075.

19 (a) S. W. Thomas, G. D. Joly and T. M. Swager, Chem. Rev., 2007, 107, 1339-1386; (b) D. Zhao and T. M. Swager, Macromolecules, 2005, 38, 9377-9384; (c) S. J. Toal and W. C. Trogler, J. Mater. Chem., 2006, 16, 2871.

20 (a) J. Liu, Y. Zhong, P. Lu, Y. Hong, J. W. Y. Lam, M. Faisal, Y. Yu, K. S. Wong and B. Z. Tang, Polym. Chem., 2010, 1, 426429.

21 H. Sohn, M. J. Sailor, D. Magde and W. C. Trogler, J. Am. Chem. Soc., 2003, 125, 3821-3830.

22 J. W. Kang, K. Moseley and P. M. Maitlis, J. Am. Chem. Soc., 1969, 91, 5970-5977. 